\title{
Detection of Hoax Spread in The Whatsapp Group with Lexicon Based and Naive Bayes Classification
}

\author{
Jordan Andrean, Suharjito
}

\begin{abstract}
Spreading hoax through WhatsApp social media can lead to different beliefs and can cause disputes for those affected. This paper proposes a hybrid model for finding hoaxes in the WhatsApp group using a combination of knowledge-based and machine learning approaches. This Hybrid model combines two methods namely Lexicon based and Naive Bayes Classifier which will be applied to the WhatsApp monitoring application. This research focuses on two main aspects namely word weighting using the lexicon based method and data classification using the Naive Bayes Classifier and Decision tree-j48 methods. The dataset used is conversation data that is crossed from the WhatsApp group. Based on the experiments that have been carried out, it is obtained the results of classification using Naive Bayes classifier of $86.670 \%$ data conversation not indicated hoaxes and $13.330 \%$ indicated hoaxes. The average value of the percentage of truth obtained more than $75 \%$. The average value of the classification performance evaluation results in a precision value of 0.771 , a recall value of 0.754 , an F-measure value of 0.773 .

Keywords : WhatsApp monitoring, Hoax, Hybrid Approach, Lexicon based, Naive Bayes Classifier.
\end{abstract}

\section{INTRODUCTION}

Information diffusion about events that occur in the community quickly prominent in a variety of social media. These social media include Wikipedia, Facebook, Youtube, Twitter, Tumblr, BBM, WhatsApp, Instagram, and many more that can be used for social media [1]. This is an opportunity for parties who have a specific purpose to spread information about events that are not yet known to be true or hoaxes. Hoax distribution is often done through WhatsApp social media because it is considered easy for the public to deliver messages and is supported by group facilities that can

accommodate more than 50 users. This causes the perpetrators of the spread of hoaxes to easily spread the hoax in the middle of the group. According to research from [2], Whatsapp application is chosen by many people (individuals, groups, organizations and even government) as a medium for delivering messages because it is considered more effective

Revised Manuscript Received on March, 282020.

* Correspondence Author

Jordan Andrean*, Magister Teknik Informatika, BINUS University , Jakarta, Indonesia

Suharjito, Magister Teknik Informatika, BINUS University, Jakarta, Indonesia.

(c) The Authors. Published by Blue Eyes Intelligence Engineering and Sciences Publication (BEIESP). This is an open access article under the CC BY-NC-ND license (http://creativecommons.org/licenses/by-nc-nd/4.0/) and is a satisfaction when the information delivered is right on target. This research utilizes the Hybrid approach to the WhatsApp monitoring application to find the source of hoax in the WhatsApp group. The Hybrid approach used is a combination of a knowledge-based and machine learning approach. This hybrid model combines two methods namely lexicon based and Naive Bayes classifier. The lexicon based method is used in the word weighting process, which is a conversation dataset from preprocessing results compared to a dataset from the lexicon dictionary so that values are obtained for each word [3]. And then, the conversation dataset is classified using the naive bayes classifier method, which results in a percentage of conversation data that is indicated to be hoaxed or not. Data indicated hoax conversation if included in the negative sentiment category and not indicated hoax if included in the positive or neutral category. The negative sentiment category means that the conversation data contains hoax elements such as using emotional and provocative language. While the positive sentiment category means that the conversation data is not indicated as a hoax because it does not contain hoax elements.

\section{RELATED WORK}

This research was conducted by [3], proposes a lexicon-based approach to conducting entity level sentiment analysis on Twitter. Through the Chi-square test on the output, tweets containing opinions can be identified. A binary classifier is then trained to assign sentiment polarity to the tweet that has just been identified, the training data provided by the lexicon-based method. A study by [4], has proposed a Machine-Human (MH) model for detecting false news on social media. This model combines a human literacy news detection tool and a machine linguistic approach and a network-based approach. The model was stated to be able to improve the ability of humans to distinguish fake news with higher accuracy than when they did without using a model. The next interesting topic raised by [5], This paper proposes a hybrid approach that combines node embeddings and user-based features to enrich the detection of SOFNs on the Twitter social network.

This research shows knowledge extracted from social network graphs using node2vec is able to provide a general way to improve social networking embeddings and more helpful in detecting SOFNs.

\& Sciences Publication

(C) Copyright: All rights reserved. 
The hybrid approach is also used for the message sentiment analysis on Twitter proposed by [6]. This approach combines two methods namely Lexicon based and Machine Learning based. Based on experiments that have been done, it is found that the use of the Lexicon based approach shows high precision but low memory causing performance problems. To improve performance, the two approaches are combined. Empirical evaluations are carried out with a variety of different training data sets to ensure that the proposed approach is very effective and better for Twitter sentiment analysis.

Table- I: Existing Approaches And Techniques

\begin{tabular}{|c|c|c|}
\hline Authors & $\begin{array}{c}\text { Approaches and } \\
\text { Techniques }\end{array}$ & Evaluation Result \\
\hline [3] & $\begin{array}{l}\text { Lexicon-based and } \\
\text { Learning-based Methods }\end{array}$ & $\begin{array}{l}\text { The ME method produces an } \\
\text { accuracy of } 0.756 \text { with a value } \\
\text { of Precision } 0.170 \text {, Recall } 0.202 \\
\text { and an F-score of } 0.184 \text {. The } \\
\text { FBS method produces an } \\
\text { accuracy of } 0.878 \text { with a value } \\
\text { of Precision } 0.564 \text {, Recall } 0.556 \\
\text { and an F-score of } 0.560 \text {. The } \\
\text { AFBS method produces an } \\
\text { accuracy of } 0.868 \text { with a value } \\
\text { of Precision } 0.522 \text {, Recall } 0.582 \\
\text { and an F-score of } 0.569 \text {. }\end{array}$ \\
\hline [4] & $\begin{array}{l}\text { Combines the human } \\
\text { literacy news detection } \\
\text { tool and the machine } \\
\text { linguistic and } \\
\text { network-based } \\
\text { approaches. }\end{array}$ & $\begin{array}{l}\text { MH }(\text { Machine Human })=\sum[\mathrm{A}+ \\
\mathrm{B}+\mathrm{C}+\mathrm{D} \ldots+\mathrm{J}] \leq 100 . \text { If the } \\
\mathrm{MH} \text { results are } \leq 100 \text { then the } \\
\text { news is true and vice versa if } \\
\mathrm{MH}>100 \text {, then false news or } \\
\text { hoaxes. }\end{array}$ \\
\hline [5] & $\begin{array}{l}\text { Twitter network analysis } \\
\text { and machine learning. }\end{array}$ & $\begin{array}{l}\text { Decission tree method produces } \\
0.927 \text { accuracy with a value of } \\
\text { Precision } 0.763 \text {, Recall } 0.781 \\
\text { and F-score } 0.928 \text {. The K-NN } \\
\text { method produces an accuracy of } \\
0.962 \text { with a value of Precision } \\
0.970 \text {, Recall } 0.777 \text { and F-score } \\
0.956 \text {. The SVM method } \\
\text { produces an accuracy of } 0.980 \\
\text { with a value of Precision } 0.976 \text {, } \\
\text { Recall } 0.765 \text { and an F-score of } \\
0.954 \text {. }\end{array}$ \\
\hline [6] & $\begin{array}{l}\text { Lexicon Based Approach } \\
\text { and Machine Learning } \\
\text { Approach. }\end{array}$ & $\begin{array}{l}\text { Training data }=5000 \text {, testing } \\
\text { data }=200 \text { produces } 60.53 \% \\
\text { unigram, } 59.38 \% \text { bigram and } \\
57.13 \% \text { trigram. }\end{array}$ \\
\hline
\end{tabular}

\section{THE PROPOSED TECHNIQUE}

Figure 1. Will show the workflow of the approach model that we propose.

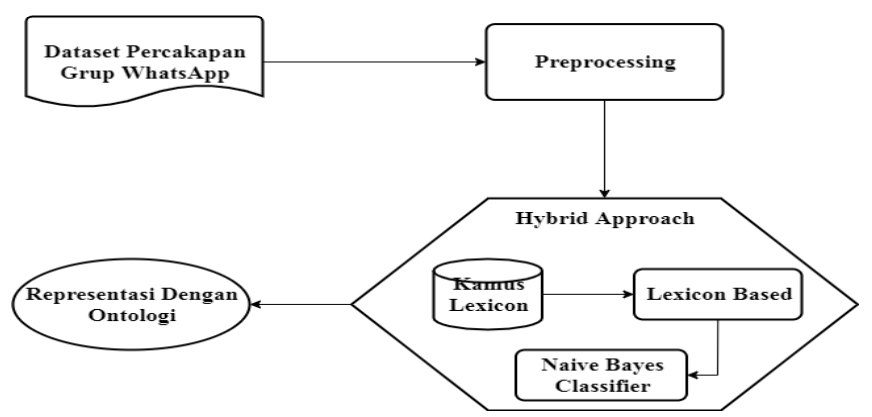

Fig. 1. Application workflow model

Fig 1. Shows the proposed application workflow model. The model includes the following steps.

\section{STEP 1: DATASET}

Conversation dataset is collected using crawling techniques through WhatsApp groups using Selenium and Redist. From the selenium tag class that initializes the group a dump process will be carried out to get the WhatsApp number, username and conversation information from that user. While Redist is used to process the session login from WhatsApp Web to generate WhatsApp Web Qrcode.

Table- II: Example of Conversation Dataset

\begin{tabular}{|c|c|}
\hline No & 1 \\
\hline User Account & +6283831286609 \\
\hline Conversation & $\begin{array}{l}\text { Can be analyzed who did the offender who insulted our } \\
\text { brother Papua, so that he could be tried quickly so that } \\
\text { the problem can be resolved quickly just dismantle the } \\
\text { account. }\end{array}$ \\
\hline $\begin{array}{l}\text { WhatsApp } \\
\text { Groups } \\
\text { Followed }\end{array}$ & $\begin{array}{l}\text { - Indonesia Bersatu } \\
\text { - WARTA TV POLRI NEWS } \\
\text { - JOKOWI SEKALI LAGI }\end{array}$ \\
\hline
\end{tabular}

Table- II shows the attributes of data that has been successfully crossed, namely the user account that contains the user's telephone number, user conversations and what groups the user has followed.

\section{STEP 2: PREPROCESSING}

The conversation data preprocessing stage consists of four stages:

\section{Case Folding}

The process for converting all uppercase contained in a conversation to lowercase.

Table- III: Case Folding Stage

\begin{tabular}{|l|l|}
\hline \multicolumn{1}{|c|}{ Conversation } & \multicolumn{1}{c|}{ Case Folding Results } \\
\hline $\begin{array}{l}\text { Can be analyzed who did the } \\
\text { offender who insulted our brother }\end{array}$ & $\begin{array}{l}\text { can be analyzed who did the } \\
\text { offender who insulted our brother }\end{array}$ \\
$\begin{array}{l}\text { Papua, so that he could be tried } \\
\text { quickly so that the problem can be } \\
\text { resolved quickly just dismantle the } \\
\text { account. }\end{array}$ & $\begin{array}{l}\text { quickly so that the problem can be } \\
\text { resolved quickly just dismantle the } \\
\text { account }\end{array}$ \\
\hline
\end{tabular}

Table- III shows the process of changing uppercase to lowercase letters in a user's conversation.

\section{Tokenizing}

The process of breaking a conversation into tokens uses delimiter spaces. 
Table- IV: Tokenizing Stage

\begin{tabular}{|l|l|}
\hline $\begin{array}{l}\text { Unigram (one } \\
\text { word) }\end{array}$ & $\begin{array}{l}\text { can, analyzed, who, the culprit, who, maki2, } \\
\text { brothers, us, papua, let, quickly, be tried, so, quickly, } \\
\text { finished, problem, this, dismantle, alone, account, } \\
\text { that }\end{array}$ \\
\hline $\begin{array}{l}\text { Bigram (two } \\
\text { word) }\end{array}$ & $\begin{array}{l}\text { can be analyzed, who is the culprit, who abuses us, } \\
\text { our brothers, Papua so that we can be tried quickly, } \\
\text { so quickly, problem is over, just dismantle, just } \\
\text { account, analyzed who, the culprit, who insulted } \\
\text { you, we Papua, so quickly, tried so quickly, this } \\
\text { problem, just dismantle it, the account }\end{array}$ \\
\hline $\begin{array}{l}\text { Trigram (three } \\
\text { word) }\end{array}$ & $\begin{array}{l}\text { Can be analyzed who, the offender is insulting, our } \\
\text { brothers and sisters in Papua, so that they can be } \\
\text { tried quickly, so that it can be resolved quickly, this } \\
\text { problem is dismantled, just that account }\end{array}$ \\
\hline
\end{tabular}

Table- IV shows the process of breaking words into three categories, namely Unigram, Bigram and Trigram. Solving words is done because a word can have different weights, for example one word entered in the unigram category and included in the bigram category will certainly have different weights.

\section{Stopwordremoval (filtering)}

The process of removing words that are considered not important, such as there are conjunctions, prepositions, pronouns, or words that have nothing to do with the sentiment of the analysis will be deleted.

Table- V: Stopwordremoval Stage

\begin{tabular}{|c|c|}
\hline Conversation & Stopwordremoval Results \\
\hline $\begin{array}{l}\text { can, analyzed, who, the culprit, } \\
\text { who, insulted, brothers, us, } \\
\text { papua, let, quickly, be tried, so, } \\
\text { quickly, finished, problem, this, } \\
\text { dismantle, just, account, that. }\end{array}$ & $\begin{array}{l}\text { can, analysis, who, the culprit, } \\
\text { insulted, brother, us, papua, fast, fair, } \\
\text { quick, finished, problem, dismantle, } \\
\text { account. }\end{array}$ \\
\hline
\end{tabular}

Table- V shows the process of omitting words that are not important that can affect the results of sentiment analysis

\section{Stemming}

The process of converting infix or suffix-filled words into a basic word becomes more specific.

Table- VI: Stemming Stage

\begin{tabular}{|c|c|}
\hline versation & Stemming Re \\
\hline $\begin{array}{l}\text { can, analysis, who, the culprit, } \\
\text { insulted, brother, us, papua, fast, } \\
\text { fair, quick, finished, problem, } \\
\text { dismantle, account. }\end{array}$ & $\begin{array}{l}\text { can, analysis, who, the offender, } \\
\text { insulting, brothers, us, Papua, so, } \\
\text { quickly, fair, fast, finished, } \\
\text { problem, dismantle, account. }\end{array}$ \\
\hline
\end{tabular}

Table- VI shows the process of changing the words that affect the root words to make the process of weighting the words easier.

\section{STEP 3: IMPLEMENTASI HYBRID APPROACH}

The proposed hybrid approach utilizes a combination of the Lexicon-based approach and the machine learning-based approach. This hybrid model combines two methods namely lexicon based and Naive Bayes classifier. The lexicon based method is used in the word weighting process, which is after going through a preprocessing process, words from the stemming results are compared with the lexicon dictionary that has been made. Furthermore, the conversation dataset is classified using the naive bayes classifier method, which results in a percentage of conversation data that is indicated to be hoaxed or not. The classification process produces three categories of sentiments, namely positive, negative and neutral. Conversation data that falls into the category of positive and neutral sentiments is indicated that the conversation data does not contain hoax elements. While the conversation data that falls into the negative sentiment category, it is indicated that the conversation data contains hoax elements.

\section{A. Lexicon Dictionary}

This is examples of some words in each lexicon dictionary used as a comparison in weighting words.

Table- VII: Emoticon Dictionary

\begin{tabular}{|l|l|c|}
\hline \multicolumn{1}{|c|}{ Emoticon } & \multicolumn{1}{c|}{ Feeling } & Quality \\
\hline$:):-)$ & Happy & 3 \\
\hline$:(:-($ & Sad & -3 \\
\hline$: \mathrm{D}:-\mathrm{D}$ & Very Happy & 4 \\
\hline $\mathrm{D}: \mathrm{D}=$ & Very Sad & -4 \\
\hline$* . * * * * * *$ & Interested & 2 \\
\hline $\mathrm{D}:<\mathrm{D}:$ & Afraid & -2 \\
\hline xD XD & Smile/Laughing & 2 \\
\hline
\end{tabular}

Table- VII is an example of some emoticons that already have values. Dictionary of emoticons can be enlarged in number. The more contents of the emiticon dictionary, the results of sentiment analysis will be better.

Table- VIII: Dictionary of Disclaimer

\begin{tabular}{|c|c|}
\hline Word & Quality \\
\hline Not yet & -2 \\
\hline Not & -3 \\
\hline Without & -3 \\
& \\
\hline No & -4 \\
\hline Abstinence & -4 \\
\hline Do not & -4 \\
\hline Never & -4 \\
\hline Arrogant & -3 \\
\hline
\end{tabular}

Table- VIII is an example of a Lexicon dictionary containing several words of denial along with the value of each word.

Table- IX: Dictionary of Question Word

\begin{tabular}{|c|c|}
\hline Word & Quality \\
\hline Who & 2 \\
\hline Where & 3 \\
\hline When & 3 \\
\hline Where & 2 \\
\hline How & 3 \\
\hline What & 2 \\
\hline Why & 3 \\
\hline Why & 2 \\
\hline
\end{tabular}

Table- IX is an example of a Lexicon dictionary which contains several question words along with the value of each word.

Table- X: Dictionary of Positive Word

\begin{tabular}{|c|c|}
\hline Word & Quality \\
\hline Good & 4 \\
\hline Great & 3 \\
\hline Clever & 3 \\
& \\
\hline Fast & 2 \\
\hline Honest & 4 \\
\hline Can & 4 \\
\hline True & 4 \\
\hline Smart & 4 \\
\hline
\end{tabular}

Table- $\mathrm{X}$ is an example of a Lexicon dictionary that contains several positive words along with the value of each word.

Table- XI: Dictionary of Negative Word

\begin{tabular}{|c|c|}
\hline Word & Quality \\
\hline Lie & -4 \\
\hline Corruption & -3 \\
\hline
\end{tabular}

Published By: 


\begin{tabular}{|c|c|}
\hline Cruel & -4 \\
\hline Ugly & -4 \\
\hline Danger & -4 \\
\hline Take a part & -4 \\
\hline Disaster & -4 \\
\hline Clash & -4 \\
\hline
\end{tabular}

Table- XI is an example of a lexicon dictionary containing several negative words along with the value of each word.

\section{B. Word Qualiting Based on the Lexicon Dictionary}

Qualiting the results of stemming is done by comparing words with the lexicon dictionary, each word will be matched with the lexicon dictionary to give value to each word. The results of word weighting can be seen in Table XII.

Table- XII: Word Qualiting Results

\begin{tabular}{|c|l|c|}
\hline $\mathbf{N}$ & \multicolumn{1}{|c|}{ Word } & Score \\
\hline n1 & Can & 4 \\
\hline n2 & Analysis & 2 \\
\hline n3 & Who & 2 \\
\hline n4 & Players & -3 \\
\hline n5 & Insulted & -4 \\
\hline n6 & Brothers & 1 \\
\hline n7 & Us & 1 \\
\hline n8 & Papua & 4 \\
\hline n9 & Fast & 2 \\
\hline n10 & Fair & 4 \\
\hline n11 & Fast & 2 \\
\hline n12 & Finish & 2 \\
\hline n13 & Problem & -2 \\
\hline n14 & Take apart & -4 \\
\hline n15 & Account & 2 \\
\hline
\end{tabular}

Table- XII shows the word weighting process, which is matching words from conversation data with words from the Lexicon dictionary to determine the value of each word in the conversation data.

\section{Determination of Sentiment Value}

Sentiment value search is performed on each word that has weight so that in one conversation will be known the total number of positive values (Spositive) and also negative values (Snegative) of each constituent word.

Look for total positive value :

$=$

$$
=+++++++++
$$

$=4+2+2+1+1+4+2+4+2+2+2$

$$
=26
$$

Look for total negative value :

$$
=
$$

$$
=+++
$$

$=4+2+2+1+1+4+2+4+2+2+2$

$=26$

After knowing the total positive and negative values, the next step is to determine the orientation of the sentiment by comparing the number of positive, negative and neutral values.

\section{Sentiment Analysis Results}

From the series of processes above it can be concluded that the conversation has positive sentiments.

Table- XIII: Conversational Sentiment Analysis Results

\begin{tabular}{|l|l|}
\hline No & 1 \\
\hline User Account & +6283831286609 \\
\hline Conversation & $\begin{array}{l}\text { Can be analyzed who did the offender who insulted } \\
\text { our brother Papua, so that he could be tried quickly } \\
\text { so that the problem can be resolved quickly just }\end{array}$ \\
\hline
\end{tabular}

\begin{tabular}{|l|l|}
\hline & dismantle the account \\
\hline WhatsApp & $\bullet$ Indonesia Bersatu \\
Groups & $\bullet$ WARTA TV POLRI NEWS \\
Followed & $\bullet$ JOKOWI SEKALI LAGI \\
\hline Sentiment & Positive \\
\hline
\end{tabular}

Table- XIII shows the results of a data sentiment analysis from a user account with the results of a positive sentiment analysis.

\section{E. Conversation Data Classification}

The classification process utilizes a machine learning based approach using the Naive Bayes classifier algorithm. The total amount of conversation data used for the classification process is 700 conversation data. The data is divided into two namely 500 conversation data as training data and 200 conversation data as testing data. Each training data has been labeled with three categories of sentiments, namely positive sentiment, negative sentiment and neutral sentiment.

Table- XIV: Training Data Classification Results

\begin{tabular}{|l|l}
\hline Precentage of correctness & Precentage of error \\
\hline
\end{tabular}
$73,3333 \%$ $26,6667 \%$

Based on Table- XIV, the percentage of correctness of the classification is $73.3333 \%$ and the percentage of errors is $26.6667 \%$. The percentage of truth is the amount of labeling the right sentiment in the training data. Table- $\mathrm{XV}$ is a performance evaluation value from the initial classification results showing a precision value of 0.756 , a recall value of 0.733 and an f-measure of 0.739 .

Table- XV: Evaluation of training data classification

\begin{tabular}{c|c|c} 
Precission & Recall & F-Measure \\
\hline 0.756 & 0.733 & 0.739 \\
\hline
\end{tabular}

\section{STEP 4: ONTOLOGY}

Ontology is used to represent data that has been processed from Hybrid Approach to find out whether the perpetrators of the hoaxes are also included in the other Whtasapp groups.

\section{EXPERIMENTAL RESULT AND DISCUSSION}

Based on the value of the percentage of errors that are still large and the value of performance evaluation that has not yet reached a value of 1 , found factors that influence the results of the classification is there is a vocabulary in the conversation that is not in the Lexicon dictionary.

Based on these factors, the training data is improved by reviewing it by adding the word sentiment to the word dictionary. After the improvement process, the results of the sentiment analysis classification are tested again.

The results of the training data classification show the truth value of $98 \%$ and the percentage of misclassification of $2 \%$. The value of the performance evaluation indicates a precision value of 0.987 , a recall value of 0.973 , an f-measure value of 0.975 .

Table- XVI: Classification Results of Testing Data

\begin{tabular}{|c|c|c|c|}
\hline \multicolumn{4}{|c|}{ Classification } \\
\hline Hybrid & Positive & Neutral & Negative \\
\cline { 2 - 4 } Approach & $34,330 \%$ & $52,330 \%$ & $13,330 \%$ \\
\hline Naive Bayes & Positive & Neutral & Negative \\
\cline { 2 - 4 } Classifier & $30,330 \%$ & $44,330 \%$ & $26,330 \%$ \\
\hline
\end{tabular}

Table- XVI shows the comparison of classification results between Hybrid Approach and Naive Bayes Classifier.

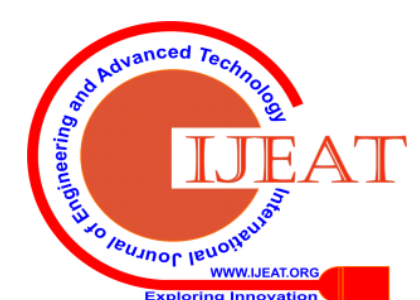


Table- XVII: Performance Evaluation of Testing Data Classification

\begin{tabular}{|c|c|c|c|c|}
\hline & \multicolumn{4}{|c|}{ classificatio } \\
\hline $\begin{array}{c}\text { Hybrid } \\
\text { Approach }\end{array}$ & Accuracy & Precision & Recall & F-measure \\
\cline { 2 - 5 } & $75 \%$ & 0,771 & 0,754 & 0,773 \\
\hline Naive Bayes & Accuracy & Precision & Recall & F-measure \\
\cline { 2 - 5 } Classifier & $68 \%$ & 0,708 & 0,702 & 0,704 \\
\hline
\end{tabular}

From the results of sentiment analysis of 200 test data, a confusion matrix table can be formed as in Table XVIII:

Table- XVIII: Matrix Confusion

\begin{tabular}{|c|c|c|c|c|}
\hline \multirow{5}{*}{$\begin{array}{c}\text { Hybrid } \\
\text { Approach }\end{array}$} & \multirow{2}{*}{ Actual } & \multicolumn{3}{|c|}{ Prediction } \\
\hline & & Positive & Negative & Neutral \\
\hline & Positive & 58 & 0 & 10 \\
\hline & Negative & 0 & 18 & 10 \\
\hline & Neutral & 0 & 20 & 84 \\
\hline \multirow{5}{*}{$\begin{array}{c}\text { Naive } \\
\text { Bayes } \\
\text { Classifier }\end{array}$} & & \multicolumn{3}{|c|}{ Prediction } \\
\hline & Actual & Positive & Negative & Neutral \\
\hline & Positive & 50 & 0 & 12 \\
\hline & Negative & 0 & 28 & 20 \\
\hline & Neutral & 0 & 25 & 75 \\
\hline
\end{tabular}

Based on the results of the two experiments above, it can be concluded that the use of Hybrid Approach shows better results than those using only the Naive Bayes Classifier method. The application of Hybrid Approach has several advantages including having a higher level of accuracy and being able to do emotion sentiment.

This is the results of the WhatsApp monitoring system design that has been implemented:

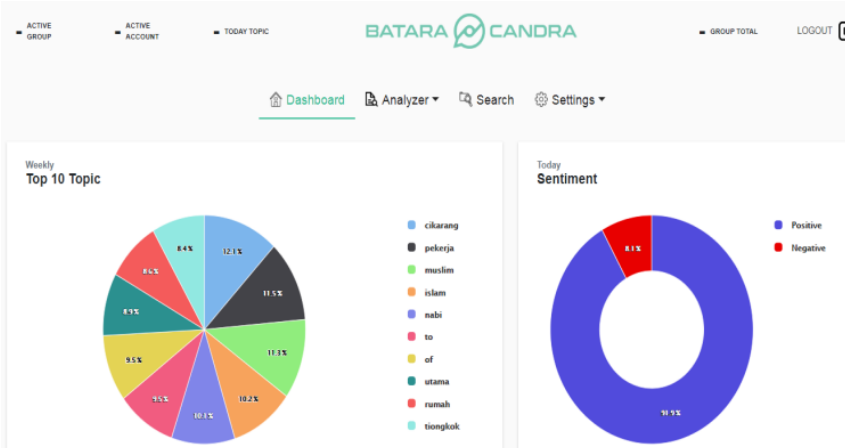

Fig. 2. The results of crawling WhatsApp group conversation topics.

Fig. 2. shows conversational topics that have been successfully crossed from all conversations in the WhatsApp group based on conversations that often appear and are used.

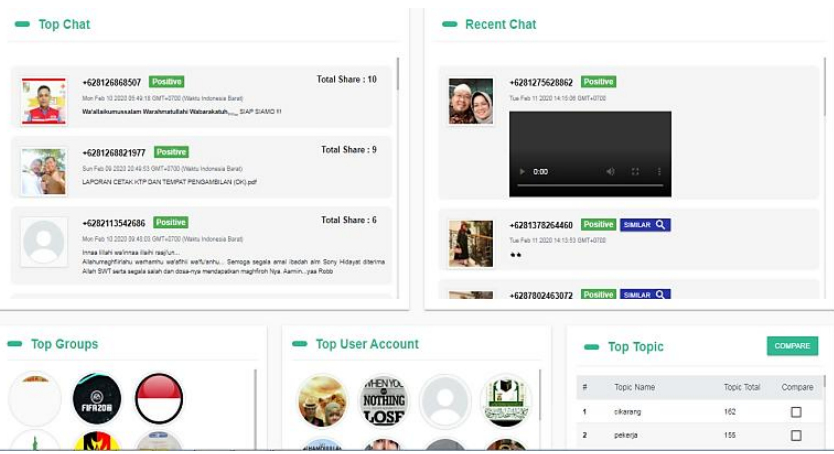

Fig. 3. The results of crawling conversations on WhatsApp groups.

Fig. 3. Shows the results of crawling conversation data consisting of Top Chat, Recent Chat, Top Groups, Top User Accounts and Top Topic.

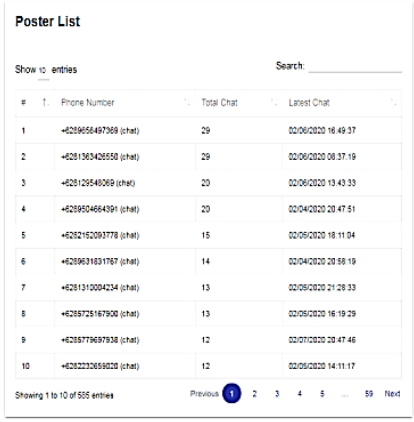

Fig. 5. User account data based on topic.

Fig. 5. Shows user account data that addresses a particular topic based on topic compare.

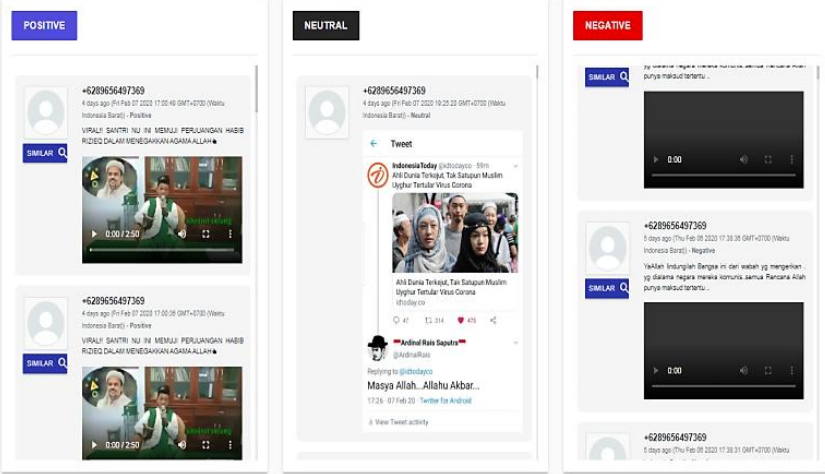

Fig. 6. The results of sentiment analysis on user accounts based on topic.

Fig. 6. shows the results of sentiment analysis on user accounts that discuss certain topics based on topic compare. The results of this analysis will be used to determine the existence of hoax indications in every conversation.

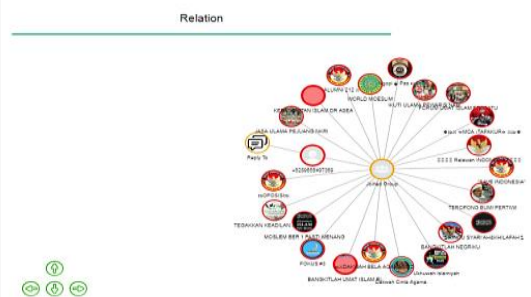

Fig. 7. Ontology representation on user accounts based on topic.

Fig. 7. Shows the ontology representation on the user account by topic, within the ontology there is a node that denotes the WhatsApp group and the WhatsApp account node that addresses the topic.

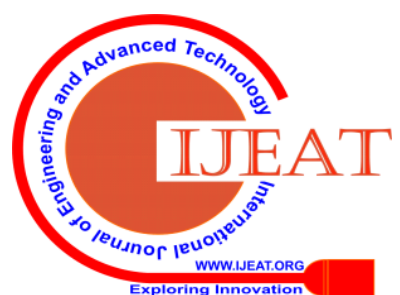




\section{CONCLUSION AND FUTURE WORK}

In this paper we propose the WhatsApp monitoring application to look for sources of hoaxes on the WhatsApp group. The experimental results show that the proposed hybrid model for detecting hoaxes is superior to hoax detection which uses only one method, the Naive Bayes Classifier.

This is also evidenced by the results of comparisons between two methods which show that Hybrid Approach has better results in terms of accuracy as well as others. The use of Hybrid Approach also has advantages such as being able to process emotion sentiment which will facilitate the detection of hoaxes from conversation data in the WhatsAppp group. In further developments, the use of the Hybrid approach can be applied to other social media platforms to detect hoaxes.

\section{REFERENCES}

1. A. S. Cahyono, "Pengaruh Media Sosial Terhadap Perubahan Sosial Masyarakat di Indonesia," pp. 140-157, 2016.

2. Trisnani, "Pemanfaatan WhatsApp Sebagai Media Komunikasi Dan Kepuasan Dalam Penyampaian Pesan Dikalangan Tokoh Masyarakat," vol. 6, 2017.

3. L. Zhang, R. Ghosh, M. Dekhil, M. Hsu, and B. Liu, "Combining lexicon-based and learning-based methods for twitter sentiment analysis," HP Laboratories Technical Report, no. 89. 2011.

4. E. M. Okoro, B. A. Abara, A. O. Umagba, A. A. Ajonye, Z. S. Isa, and N. A. I. Nstitute, "A Hybrid Approach to Fake News Detection on Social Media,” vol. 37, no. 2, pp. 454-462, 2018.

5. T. Hamdi, H. Slimi, I. Bounhas, and Y. Slimani, "Hybrid Approach Based on Graph Embedding and Users Features to Detect Source of Fake News in Twitter Social Network Using Machine Learning.,"

6. V. Nandi and S. Agrawal, "Sentiment Analysis using Hybrid Approach,” Int. Res. J. Eng. Technol., pp. 1621-1627, 2016.

7. B. Kaur and N. Kumari, "A Hybrid Approach to Sentiment Analysis of Technical Article Reviews,” Int. J. Educ. Manag. Eng., vol. 6, no. 6, pp. 1-11, 2016

8. A. Altaher, "Hybrid approach for sentiment analysis of Arabic tweets based on deep learning model and features weighting," Int. J. Adv. Appl. Sci., vol. 4, no. 8, pp. 43-49, 2017.

9. J. Z. Pan, S. Pavlova, C. Li, N. Li, Y. Li, and J. Liu, "Content based fake news detection using knowledge graphs," Lect. Notes Comput. Sci. (including Subser. Lect. Notes Artif. Intell. Lect. Notes Bioinformatics), vol. 11136 LNCS, pp. 669-683, 2018.

10. Z. Zhou, H. Guan, M. Bhat, and J. Moorthy Hsu, "Fake News Detection via NLP is Vulnerable to Adversarial Attacks," 2015.

11. T. Granskogen and J. A. Gulla, "Automatic Detection of Fake News in Social Media using Contextual Information," 2018.

12. P. Kussa Laksana Utama, "Identifikasi Hoax pada Media Sosial dengan Pendekatan Machine Learning," Widya Duta J. Ilm. Ilmu Agama dan Ilmu Sos. Budaya, vol. 13, no. 1, pp. 69-76, 2018.

13. C. Boididou, S. Papadopoulos, M. Zampoglou, L. Apostolidis, O. Papadopoulou, and Y. Kompatsiaris, "Detection and visualization of misleading content on Twitter,” Int. J. Multimed. Inf. Retr., vol. 7, no. 1, pp. 71-86, 2018.

14. M. Cs and A. Justitia, "Sistem Deteksi Hoax Dengan Menggunakan Algoritma Naïve Bayes," pp. 94-95, 2018.

15. Sani M Isa, "Sentiment Analysis Approaches and Methods," BINUS, 2017. [Online]. Available: https://mti.binus.ac.id/2017/10/04/1900/. [Accessed: 29-Jul-2019].

16. S. Lorent and A. Itoo, Fake News Detection Using Machine Learning. 2019.

17. J. C. S. Reis, A. Correia, F. Murai, A. Veloso, and F. Benevenuto, "Explainable machine learning for fake news detection," WebSci 2019 - Proc. 11th ACM Conf. Web Sci., pp. 17-26, 2019.

18. A. Drif, Z. F. Hamida, and S. Giordano, "Fake News Detection Method Based on Text-Features," no. c, pp. 26-31, 2019.

19. P. Kaur, R. S. Boparai, and D. Singh, "A Review on Detecting Fake News through Text Classification,” pp. 393-406.

20. K. Shu, A. Sliva, S. Wang, J. Tang, and H. Liu, "Fake News Detection on Social Media," ACM SIGKDD Explor. Newsl., vol. 19, no. 1, pp. 22-36, 2017.

21. R. J. Poovaraghan, M. V. K. Priya, P. V. S. S. Vamsi, M. Mewara, and S. Loganathan, "Fake News Accuracy using Naive Bayes Classifier," Int. J. Recent Technol. Eng., vol. 8, no. 1C2, pp. 962-964, 2019. BINUS University.

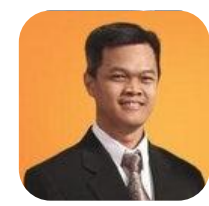
software engineering processing and is pursuing an information technology education program at the S2 level at

Suharjito is the Head of Computer Science Department in Binus Online Learning Program of Bina Nusantara University. He received under graduated degree in mathematics from The Faculty of Mathematics and Natural Science in Gadjah Mada University, Yogyakarta, Indonesia in 1994. He received master degree in information technology engineering from Sepuluh November Institute of Technology, Surabaya, Indonesia in 2000. He received the PhD degree in system engineering from the Bogor Agricultural University (IPB), Bogor, Indonesia in 2011. His research interests are intelligent system, Fuzzy system, image processing and 